\title{
The present situation and the research direction of the Wushu curriculum in the private schools
}

\author{
Chen Wang \\ Sports Section,Xi'an Fanyi University,Xi'an710105,Shaanxi, China
}

Keywords: Private college, Wushu Course, Countermeasures.

\begin{abstract}
Through the research on Sanda curriculum in private colleges in Shaanxi Province, to analyze the problems encountered in the process of all opened Sanda curriculum in private colleges in Shaanxi Province, in combination with the guiding ideology of lifelong physical education, provide powerful reference for the development of private education in Shaanxi province and the curriculum reform, and provide reference for the sustainable development of pr.
\end{abstract}

\section{Introduction}

The rise of private higher education in our country, since China's reform and opening up, an imp ortant achievement of education reform and innovation, marked the our country higher education en terprise began to enter a new stage of diversified development. Inadequate public education in our c ountry, public education resources is difficult to fully meet the demand of public education under th e background of diversification, private higher education in our country apply market mechanism, $s$ elf-raised funds, run independently and changed after the founding of the pattern of running schools in the form of government for a long time. At the same time, it has cultivated tens of thousands of a pplied and skilled talents for the first line of socio-economic and cultural development, and promote $\mathrm{d}$ the popularization of the education in China. The development of private colleges and universities has become an important part of our universities. Martial arts this course as a compulsory option co urses, through the martial arts teaching, enables students to fully understand the development of wu shu sports, fully grasp the basic knowledge and skills of wushu sports, to improve students' interest in martial arts sports and hobbies, to raise the level of appreciation of martial arts, vigorously promo te the development and popularization of wushu movement. Through teaching, improve students' se lf-defense ability, hone their own will, cultivate students' moral sentiment, promote the students' ph ysical and mental health development, learn. All-round development of students' physical quality pr actice, cultivate the students ability to exercise consciousness, improve the quality of wushu culture accomplishment and life, lay a good foundation beneficial for lifetime sports, become a sound const itution, both inside and outside and repair, the comprehensive development of students. Therefore, $\mathrm{t}$ he university offers martial arts courses, with the advantages of tianshi, geography and people, whic $\mathrm{h}$ can help the spread and development of wushu culture.

\section{Overview}

Wushu is the main content of martial arts, which focuses on the traditional Chinese sports in both domestic and foreign countries. Firstly, wushu is a traditional Chinese technique. It is a play, play, fall off, take, strike, tingling and combat action as the main content, by hand or with the help of the instrument body movements to express the offensive and defensive combat ability. Whether it is confrontational or not, it is the traditional Chinese technique that is the core of the technique. Secondly, wushu is a sport. It is clearly different from the practical technique of causing injury. Although there is a rich technique in the routine, the aim is to improve the person's physical and defense ability through practice. Thirdly, wushu is an excellent national culture. Any sports program has cultural significance, but nothing The project is like martial arts with strong cultural characteristics and national color. Is one of the traditional martial arts, inherent, it breeds in the 
overall atmosphere of national culture, production, dating back to the development, dissolve naturally wired to learn, philosophy, traditional Chinese medicine, ethics, art and aesthetics, qigong and other traditional cultural thoughts and cultural ideas, pay attention to the inside and outside and repair, such as whole, change of Yin and Yang, appearance-verve theory, the theory of gas, action, firm soft and so on, gradually formed a unique national style of martial arts culture system. In the consideration of popularization and promotion of Chinese wushu movement "yu-fang zhou, Meng Shaohua. Guo-qing shen author [J]. Journal of Beijing sports university, 2007, 45 (01) - 48 Meng Shaohua pointed out in the" martial arts is a national treasure, quintessence, is an important component of excellent traditional culture, martial arts class teaching is not just a single wear technology transfer, but the mind of a national culture, traditional education process. It can play in the process of man's all-round development the unique functions and role ". "Martial arts teaching to students' physical quality, mental health and social adaptation ability has an irreplaceable role, with other sports is also carry forward Chinese traditional culture and patriotism education for students of very good method." Wang in the training in the martial arts teaching present situation and countermeasure research [J]. Journal of binzhou vocational college, 2009 (01) : 56-57. Pointed out in the vast majority of colleges and universities in sports teaching will be listed in the syllabus, martial arts not only provides some teaching hours, and formulate the specific evaluation methods and standards. Studies of martial arts teaching a handful, including tie-liu wang had to martial arts teaching in public physical education in colleges and universities are discussed in this paper, the feasibility of the thought male body class of martial arts teaching in colleges and universities should adjust martial arts teaching content. The method and method of implementing the education in the teaching of wushu are put forward by huang chunlin in combination with the teaching practice. Huang di has studied the anxiety psychology of high school students in martial arts, and put forward some concrete measures. Therefore, although wushu is most attractive to the students' value, the relevant teaching content is very short. In the end, it is urgent to organize and study the study of martial arts courses in universities. Fight martial arts activities in colleges and universities must be integrated to the related content, from the writing, the choice of the content of teaching material, teaching methods of using, formulation of rules, etc., all need to be developed suited to the characteristics of the college students, in conformity with the spirit of college sports and martial arts curriculum project characteristics, ethnic characteristics.

\section{Method}

Literature. According to the research content of this article, I refer to the various provinces and cities in recent 10 years about local colleges and universities to carry out the martial arts teaching present situation and development countermeasures of research literature, books on martial arts teaching and training, from access to a after 2000 about the present situation of ordinary university martial arts teaching journals and newspaper articles, and learn to master the research status quo and dynamic.

Questionnaire survey. In the form of questionnaire survey in Shanxi Province the current situation of martial arts courses in 10 private colleges, students like martial arts, the school field and staffed, the match held by school, and emphasis on martial arts teaching activity, teachers to attend refresher training information, etc. For 10 private colleges in shaanxi research, we designed two kinds of questionnaire, the questionnaire for teachers we have 20, 63 questionnaires taken back, the recovery rate is $90 \%$, and 61 valid questionnaires, the effective rate was $87.1 \%$. The student questionnaire was issued 600 copies, recovered 574, the recovery rate was $95.7 \%$, the effective questionnaire was 545, and the efficiency was $90.8 \%$. The distribution is illustrated. 
Table 1 Questionnaire distribution analysis

\begin{tabular}{lccccc}
\hline The questionnaire types & $\begin{array}{c}\text { The number } \\
\text { of }\end{array}$ & $\begin{array}{c}\text { The } \\
\text { recycling } \\
\text { number }\end{array}$ & The recovery rate of(\%) & $\begin{array}{c}\text { Number of } \\
\text { valid } \\
\text { questionnaires }\end{array}$ & $\begin{array}{c}\text { To be } \\
\text { efficient(\%) }\end{array}$ \\
\hline $\begin{array}{l}\text { The teacher questionnaire } \\
\text { The student questionnaire }\end{array}$ & 600 & 18 & 90 & 15 & 87.1 \\
\hline
\end{tabular}

The validity of the questionnaire was verified by the relevant experts in order to ensure the validity of the questionnaire. Conclusion: this questionnaire is easy to understand, reflects the purpose of investigation, and also has good feasibility.

Expert interviews. In order to get more information about the interview about colleges and universities sports teaching experts and competent leadership and solicit their opinions and Suggestions of the teacher, the research contents and methods of the thesis is determined.

Logical analysis. By applying the method of logical induction, deduction, analogy method such as the comprehensive data logic analysis method, the data collection and analysis to ensure that the structure of the thesis is rigorous and rationality, the feasibility of xi 'an private colleges martial arts courses provide a reasonable, healthy and orderly. Logical and logical analysis of the information obtained in the survey data and interviews.

Data statistics. Using Excel spreadsheets to collate the information and data collected by the analysis, the SPSS16.0 software is also used to analyze the data.

\section{Result}

In August, 2002 countries have enacted the national ordinary higher school physical education curriculum teaching know outline, in the sports teaching in colleges and universities, from tsinghua university to the general local colleges and universities have to martial arts on the physical education curriculum teaching in the project. Based on the status of private colleges do well promote private martial arts teaching, martial arts on the preparation before class, whether prepared fully is the key to promote martial arts teaching condition, also is the fundamental guarantee of martial arts teaching task in the teaching, should always take the student as the main body, martial arts teachers give full play to the leading role in teaching. How to play of the teachers' leading role, will directly affect the effect of wushu teaching, therefore the teacher's leading role play how to, can give full play to students' subjective initiative, it is very important. In the basic construction of the private schools in xi 'an city, the construction of the stadium and the construction of the site have been compared to the public schools. Martial arts teaching in private colleges and universities to carry out the required field will with taekwondo hall, body exercise, aerobics venues comprehensive use, so in the survey found that xi 'an private colleges and universities can provide good training for wushu teaching in teaching field. 
Table 2 The situation of the indoor courts of the private schools in shaanxi province

\begin{tabular}{cc}
\hline The school & Site number \\
\hline Xi 'an translation college & 4 \\
Xi 'an Eurasian college & 3 \\
Xi 'an foreign affairs college & 2 \\
Institute of xiking & 4 \\
Xi 'an peihua college & 3 \\
Xi 'an siyuan college & 0 \\
Shaanxi international business school & 2 \\
Xi 'an east Asia Pacific vocational and technical college & 1 \\
Xian haitang vocational technical college & 1 \\
Shaanxi electronic science and technology vocational college & 1 \\
\hline
\end{tabular}

Found in survey of xi 'an 10 private colleges, grassroots leaders and teachers are all very approve of wushu classes in physical education, but school leaders to open a martial arts teaching in physical education curriculum is a different attitude. Of the 10 schools under investigation, there are different forms and methods for the teaching of taekwondo. In the 10 colleges and universities surveyed, with xi 'an translation college, xi 'an foreign affairs college, xi 'an PeiHua college, xi 'an siyuan college in the martial arts teaching in physical education, not to carry out the other 6 colleges, analysis reason, through the competent teaching in colleges and universities, the head of the investigation and interview learned that $40 \%$ of the manager think learning martial arts can influence the school security problems, and create a certain security problems between.

Table 3 The director of the investigation department is responsible for the knowledge of the martial arts movement

\begin{tabular}{cccccc}
\hline content & $\begin{array}{c}\text { Young people like } \\
\text { projects }\end{array}$ & $\begin{array}{c}\text { The traditional } \\
\text { culture }\end{array}$ & Self-defense and health & Afight & $\begin{array}{c}\text { A } \\
\text { combined }\end{array}$ \\
\hline $\begin{array}{c}\text { The nuber of } \\
\text { The }\end{array}$ & 1 & 3 & 4 & 2 & 10 \\
percentage(\%) & 10 & 30 & 40 & 20 & 100 \\
\hline
\end{tabular}

Table 4 To study the impact of the scattered schools on the safety of the school

\begin{tabular}{cccccc}
\hline view & Will definitely & May be & Inuisible factors & Will not & $\begin{array}{c}\text { A } \\
\text { combined }\end{array}$ \\
\hline The nuber of & 4 & 2 & 3 & 1 & 10 \\
The percentage(\%) & 40 & 20 & 30 & 10 & 100 \\
\hline
\end{tabular}

Through the analysis of the data in Table 4, we can see that in the colleges and universities, $40 \%$ of surveyed responsible leadership don't want to open a martial arts in the school of physical education teaching contents, $10 \%$ of leaders hold a neutral attitude. Some colleges once opened the martial arts teaching, officials said, if in the school caused serious vicious fight, will consider opening of martial arts courses. Through the survey of teachers in 10 civil schools in xi 'an city, it is found that there are fewer teachers who have a full degree in training. Main reason is that in more than 30 years of martial arts, martial arts sport is relatively late to enter colleges and universities sports, so early on in the process of teacher training is relatively weak for martial arts teacher's cultivation. With the development of education in recent years, the sport of wushu has flourished, and various sports colleges have produced a large number of martial arts teachers in universities. In record Numbers of teachers were surveyed, can be engaged in the teaching of martial arts than three distribution, other projects into wushu sanda is $12.5 \%$, only $23 \%$ of wushu teaching, with $64.5 \%$ of wushu. Combination with the existing physical education teachers structure analysis, it can be seen that the teacher group are widespread a less quantity, low level of professional titles, and the structure characteristics of younger, more professional transformation. 


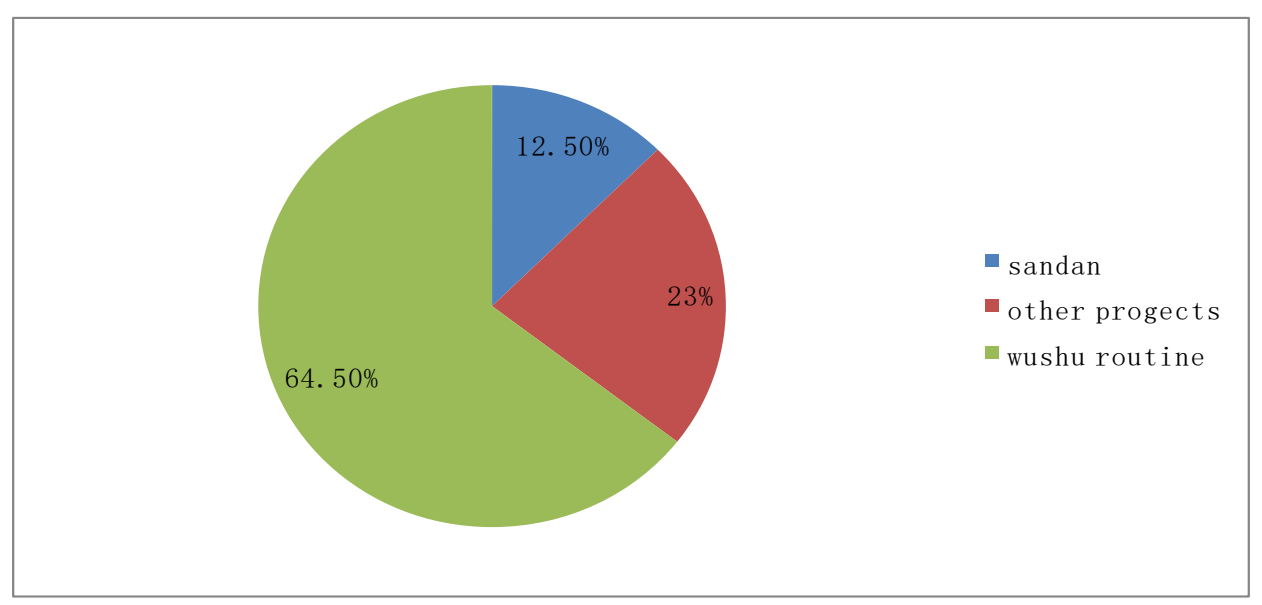

Fig.1 The teacher first specialized in the analysis

In through the survey of xi 'an 10 private colleges, some use of teaching materials is the teaching material of "sports and health", and the use of the university sports curriculum the teaching material, and using the "martial arts" copy of part of martial arts in the textbooks. In the four schools that teach martial arts, the teaching materials are taught by themselves. Some students have their own teaching CDS or teaching video. However, from the principle of teaching and training, it is not suitable for college students' use, and there is also the old age of material contents, which is not conducive to the cultivation of talents in the new era. In recent years, the martial arts in the government and the masses of workers and fans, with the help of the development and change rules of new adjustment, but for the present teaching material usage is very unfavorable to make students grasp of the latest knowledge structure system. The survey information is shown in Table 5.

Table 5 Students use the textbook analysis

\begin{tabular}{ccccc}
\hline Material usage & $\begin{array}{c}\text { Provisions of the } \\
\text { teaching material }\end{array}$ & $\begin{array}{c}\text { The textbook } \\
\text { is compiled }\end{array}$ & DVD video & There is no \\
\hline The nuber of & 193 & 172 & 23 & 157 \\
percentage $(\%)$ & 35.4 & 31.6 & 4.2 & 28.8 \\
\hline
\end{tabular}

In the process of investigation, we can see less teaching experience exchange between private colleges, the main problem is the head of the school education leaders think sports teaching communication is unnecessary, so for the development of physical education play a role. By investigating 10 non-governmental schools physical education curriculum in the martial arts sports five considered security issues, there are two say technology problem, one that is other issues, there are two considered funds problem, so for the development of wushu sport is quite bad.

Table 6 The school led an investigation into the cause of martial arts

\begin{tabular}{cccccc}
\hline reason & Seurity issues & $\begin{array}{c}\text { Technical } \\
\text { problems }\end{array}$ & $\begin{array}{c}\text { Technical } \\
\text { problems }\end{array}$ & $\begin{array}{c}\text { other } \\
\text { problems }\end{array}$ & A combined \\
\hline $\begin{array}{c}\text { The nuber of } \\
\text { percentage } \\
(\%)\end{array}$ & 5 & 2 & 2 & 1 & 10 \\
\hline
\end{tabular}

Among the many factors, the objection can only be a part of it, and it can't prevent students from learning and exercising at all. After learning to practice, it is only through the best way to practice is the assessment of learning effects, but the survey found that universities in xi 'an for martial arts competition, private colleges and universities participate in less, mostly public colleges and universities are involved in. So there is no opportunity for the exchange and comparison between the brothers and colleges. Between private colleges and universities is also a lack of "friends" to chance, and daily teaching experience are less stay, so there is no common progress, common development. 


\section{Conclusion}

Through the study of wushu courses in the civil schools in xi 'an, the students can find that the students are very enthusiastic about the wushu movement. The students' study of martial arts is mainly focused on fitness and prevention activities. The lack of wushu teachers in schools and the weak and weak faculty members lack the backbone teachers.In private colleges in shaanxi province, for the introduction of teachers has become the focus of each college development, so teachers play a key role for the martial arts courses, there is no greater impact. Between the private colleges, mutual exchange of teaching is too little, the school leadership and support the government's lack of sports wushu is influencing and restricting the development of project teaching objective reasons,

\section{References}

[1] Wang lihui [D]. Shandong normal university, 2007CNKI: 3-4 + 10

[2] Li ning, Chinese traditional wushu sustainable development study [D]. Shandong normal university, 2009CNKI.

[3].QinZilai,The present situation and countermeasures for the teaching of martial arts in general universities [J]. Journal of Beijing sports university. 2007 (2008) : 68-70.

[4] Liu Wanbin. Theory of traditional health care sports in colleges and universities of TCM education $[\mathrm{J}]$ national colleges and universities of Chinese medicine in the position of the first report on traditional health care sports. Southwest jiaotong university press, 1993 (7) 36 to 39

[5] CuiHaolan, Research on the teaching and reform of martial arts in universities [J]. Journal of wuhan college of sports, 2005 (12) 102-104

[6] Beijing promotes "the national minority student series wushu aerobics" status and strategy study author: GaoGuanfa, [D]. Beijing sports university 2012CNKI.

[7]ZhouYufang,Journal of the Chinese martial arts movement. [J]. Journal of Beijing sports university, 2007, (1) 45-48

[8] university student: the author of the cognitive study of martial arts: Mao Xuejiao[D]. Soochow university 2012CNKI.

[9] General university, the author of the research on strengthening the charm of wushu teaching: Lu yanling [D]. Nanjing normal university, 2008CNKI.

[10]Qu wenqian, The journal of the university of South Africa. [J].2007,6:93-94.

[11] Liu wanbin,The interactive development of the western minority national sports and the western university sports course. [J], 2003 (10) 453-456.

[12]Chu Haiyue.,Run by the local of guangdong province ordinary university sports teaching present situation investigation and study [J]. Journal of chifeng institute (natural science edition), 2008 (6) : 34-36. 